\title{
Groundwater transport and the freshwater-saltwater interface below sandy beaches
}

Tyler B. Evans ${ }^{1}$ and Alicia M. Wilson ${ }^{1}$

\author{
${ }^{1}$ Department of Earth and Ocean Sciences, University of South Carolina
}

701 Sumter Street, EWS 617

University of South Carolina

Columbia, SC 29208 


\section{Abstract}

Current conceptual models for groundwater flow in beaches highlight an upper saline plume, which is separated from the lower salt wedge by a zone of brackish to fresh groundwater discharge. There is currently limited knowledge of what conditions allow an upper saline plume to exist and what factors control its formation. We used variable-density, saturated-unsaturated, transient groundwater flow models to investigate the configuration of the freshwater-saltwater interface in beaches with slopes varying from 0.1 to 0.01 . We also varied hydraulic conductivity, dispersivity, tidal amplitude and inflow of fresh groundwater. The simulated salinity configuration of the freshwater-saltwater interfaces varied significantly. No upper saline plumes formed in any beach with hydraulic conductivities less than $10 \mathrm{~m} / \mathrm{d}$. The slope of the beach was also a significant control. Steeper beach faces allowed stronger upper saline plumes to develop. Median sediment grain size of the beach is strongly correlated to both beach slope and permeability, and therefore the development of an upper saline plume. Prior studies of groundwater flow and salinity in beaches have used a range of theoretical dispersivities and the appropriate values of dispersivity to be used to represent real beaches remains unclear. We found the upper saline plume to weaken with the use of larger values of dispersivity. Our results suggest that upper saline plumes do not form in all beaches and may be less common than previously considered. 


\section{Introduction}

Submarine groundwater discharge (SGD) has been shown to be a major contributor of nutrients, carbon and trace metals to the coastal ocean (Johannes, 1980; Whiting and Childers, 1989; Valiela et al., 1990; Krest et al., 2000; Burnett, 2001; Paytan et al., 2006; Moore, 2010). Sandy beaches and beaches comprised of a mixture of sand and pebble make up approximately $75 \%$ of ice-free coastlines (Brown and McLachlan, 2002). Due to the global presence of beaches, groundwater flow in beaches is an integral constituent of near-shore SGD. Significant volumes of water are transported through beach aquifers by tidal pumping (Robinson et al., 2007a; Santos et al., 2010, Santos et al., 2011) and by discharge of fresh groundwater from terrestrial watersheds (Kim and Hwang, 2002; Burnett et al., 2003; Taniguchi and Iwakawa, 2004; Santos et al., 2011). Wave forcing and wave set-up creates hydraulic gradients, also driving significant groundwater flow in the beach aquifer (Longuet-Higgins, 1983; Li and Barry, 2000; Sorenson, 2006; Xin et al., 2010). A distinct freshwater-saltwater interface develops in the beach subsurface where terrestrially derived fresh groundwater and recirculating seawater mix. Moore (1998) termed the salt-freshwater mixing zone in a coastal aquifer the subterranean estuary, emphasizing similarities between surficial estuaries and the shallow groundwater system with respect to physical and biogeochemical processes. Redox gradients and the availability of dissolved nutrients in the subterranean estuary drive geochemical transformations (Buddemeier, 1996; Moore, 1996; Charette and Sholkovitz, 2002). Short residence times and rapid flow rates of recirculating seawater drive significant mixing in the beach aquifer, driving chemical fluxes across the aquifer-ocean interface (Uchiyama et al., 2000, 
Ullman et al., 2002). Further knowledge of the hydrologic processes that occur in these subterranean estuaries is necessary for quantifying coastal geochemical budgets. mixing between fresh groundwater and seawater in the subterranean estuary (Galeati et al., 1992; Xue et al., 1995; Lebbe, 1999; Vandenbohede and Lebbe, 2006). This mixing between groundwater bodies is important as it sets up the potential for geochemical transformations to

51 occur. The classic conceptual model for groundwater flow and solute transport under a beach

52 describes flow of land-derived fresh groundwater toward the ocean, forming a salt-wedge,

53 defined as a Ghyben-Herzberg freshwater-saltwater interface (Fig. 1a). Seaward of this interface,

54 seawater recirculation through the aquifer is driven by differences in fluid density (Ghyben,

55 1889; Herzberg, 1901; Cooper 1959). Studies as recent as 10 years ago describe a salt-wedge

56 freshwater-saltwater interface with no upper saline plume (Cartwright, 2004; Boehm et al.,

57 2006). Field measurements from a sandy beach in Cape Henlopen, Delaware, suggest the

58 presence of a complex mixing zone and nutrient diagenesis between terrestrial groundwater and recirculating seawater at the lower salt wedge (Ullman et al., 2002).

Other studies have significantly revised this conceptual model. In some beaches an upper

61 saline plume (Fig. 1b) exists adjacent to the classic saltwater wedge, separated by an upward

62 flow zone (freshwater tube) that discharges near the average low tide mark on the beach

63 (Boufadel, 2000; Robinson et al., 2006b). Frequent tidal inundation of the beach surface allows

64 saline water to infiltrate into the subterranean estuary and develop a plume of higher density

65 water above less dense, fresher groundwater below. The upper saline plume is now a fixture of

66 modern conceptual models for groundwater flow below beaches (Bratton, 2010; Santos et al.,

67 2012; Thorn and Urish, 2013). 
The configuration of the salinity distribution of the freshwater-saltwater interface has

69 important implications for groundwater mixing and geochemistry in the subterranean estuary.

70 Robinson et al. (2006a) showed that a beach with an upper saline plume can support a more

71 dynamic zone of mixing in the subsurface than beaches with no upper saline plume. Oxygenated,

72 recirculated seawater mixes with reduced groundwater and sets up a redox/pH potential for

73 chemical transformations (Slomp and Cappellen, 2004; Spiteri et al., 2005). Fully defining the

74 impact of upper saline plumes will require additional field monitoring, which in turn requires the

75 ability to predict where an upper saline plume is likely to develop.

76 Motivated by the absence of the upper saline plume in several studies, as well as our own

77 field site on Sapelo Island, Ga, we hypothesized that upper saline plumes do not exist in all

78 beaches and their formation is controlled by major hydrogeologic properties such as beach slope,

79 permeability, tidal amplitude, dispersion and fresh groundwater input. We constructed variable-

80 density, saturated-unsaturated, transient groundwater flow models to perform a sensitivity

81

analysis of the major factors controlling groundwater flow and salinity distribution in beaches.

\subsection{Groundwater exchange below beaches}

84

Although previous studies have not directly tested the effects of flow on the configuration of the salt distribution of the freshwater-saltwater interface, they have investigated the driving

87 forces for flow through a beach. Robinson et al. (2007a) studied the rate of water exchange

88 across the aquifer-ocean interface as driven by tidal pumping. They performed a sensitivity analysis of major nondimensional parameters related to tidally driven and density driven 
90 recirculation (TDR and DDR, respectively) in beach aquifers. TDR pertains to flow through the

91 subterranean aquifer that is driven by tidal forcing across a sloping beach face and is defined as

92 the ratio of total infiltration due to tidal forcing to terrestrially-derived groundwater flux. DDR

93 refers to density-driven convection of seawater through the beach aquifer driven by the strength

94 of salinity gradients and is similarly defined as the ratio of total infiltration due to density-driven

95 convention to terrestrially-derived groundwater flux. Of particular interest here is the

96 nondimensional ratio of the width of the intertidal zone to tidal propagation distance (Li et al.,

97 2000; Robinson et al., 2007a):

$$
\varepsilon=A \cot (\beta) \lambda
$$

99 where $\mathrm{A}$ is tidal amplitude, $\beta$ is beach slope and $\lambda$ is the tidal propagation distance:

$$
\lambda=\sqrt{\frac{n_{e} \omega}{2 K H}}
$$

101 where $n_{e}$ is effective porosity, $\omega$ is tidal period, $\mathrm{K}$ is hydraulic conductivity and $\mathrm{H}$ is aquifer

102 depth. The distance described by equation (2) reflects the amplitude dampening of a tidal

103 groundwater wave as it propagates into a beach aquifer (Nielsen, 1990). Robinson et al., (2007a)

104 held all parameters in equation (1) constant except beach slope ( $\beta$ ) and tidal amplitude (A), both

105 of which changed the horizontal shoreline excursion. Increasing the beach slope (decreasing $\varepsilon$ )

106 generally decreased TDR rates in the beach aquifer and increased DDR. The effect of changing $\varepsilon$

107 on pore water salinity distribution and the resulting type of freshwater-saltwater interface was

108 not explicitly examined, but we hypothesized that $\varepsilon$ largely controls the development of an upper

109 saline plume in the subterranean estuary. 


\section{Numerical models}

Simulations of tidally influenced flow and solute transport processes were conducted using SUTRA (Voss and Provost 2002). SUTRA is a finite element groundwater modeling program that simulates variable-density, saturated-unsaturated fluid flow and transport of a single solute. We used a modified version to account for changes in total stress associated with tidal fluctuations (Wilson and Gardner 2006). The governing equation in the models is a form of the Richards equation

$$
\nabla \cdot[K(\Psi) \nabla h]=S_{w} S_{S} \frac{\partial h}{\partial t}+\varphi \frac{\partial S_{w}}{\partial t}-\alpha_{s} S_{w} \frac{\partial \sigma_{T}}{\partial t}
$$

where $K$ is hydraulic conductivity, $\Psi$ is negative pressure head, $h$ is hydraulic head, $S_{w}$ is water saturation, $\varphi$ is porosity, $\sigma_{T}$ is total stress and $S_{S}$ is the specific storage,

$$
S_{s}=\rho g\left(\alpha_{s}+\varphi \beta\right)
$$

where $\rho$ is the density of water, $g$ is gravity, $\alpha_{s}$ is sediment compressibility and $\beta$ is fluid compressibility.

Five model domains were created with beach slopes across the intertidal zone of 0.01 , $0.025,0.05,0.075$ and 0.1 to determine the effect of beach slope on groundwater flow and salt transport. This range of beach slopes was chosen to be representative of a range of real beaches (Bascom, 1959; Creed et al., 2000; McLachlan and Dorvlo, 2005). The five simulation domains contained a number of nodes ranging from a maximum of 11,707 and a minimum of 8,215 . The number of elements ranged from a maximum of 11,443 to a minimum of 7,962 . Element size 
132 varied from a maximum of $1 \mathrm{~m}$ to a minimum of $50 \mathrm{~cm}$ in the intertidal zone, where flow rates 133 were the greatest, to ensure the Peclet and Courant criteria were met. The baseline simulation 134 had a porosity value of 0.43 and permeability of $1.2 \times 10^{-11} \mathrm{~m}^{2}$, which is equivalent to a 135 hydraulic conductivity of approximately $10 \mathrm{~m} / \mathrm{d}$. Tidal amplitude was $1 \mathrm{~m}$ and the beach slope was 0.5 . We chose a baseline freshwater flux of $7.6 \times 10^{-7} \mathrm{~m}^{3} / \mathrm{s}$, which was also used in

137 Robinson et al. (2007a). Longitudinal and transverse dispersivity for the baseline simulation were 10 and $1 \mathrm{~m}$ respectively. All of the five domains were then run through a sensitivity analysis that included a range of values for tidal amplitude, dispersivity, inflow of fresh water and permeability (Table 1). The values of the parameters tested were again selected to be representative of those found in real beaches. Permeability values for sandy beaches are likely to 142 vary from approximately $10^{-12}$ to $10^{-10} \mathrm{~m}^{2}$ (Wilson et al., 2008). We tested longitudinal 143 dispersivity values that ranged from 0.5 to $10 \mathrm{~m}$ and held $\alpha_{\mathrm{L}} / \alpha_{\mathrm{T}}$ constant at a value of 10 (Gelhar 144 et al., 1992; Robinson et al., 2006b; Robinson et al., 2007a). We varied tidal amplitude from 0 to $1451.5 \mathrm{~m}$. In our simulations, temperature remained constant; therefore dynamic viscosity was also 146 constant. There is slight variability in the hydraulic conductivity due to variations in density 147 between fresh and saline pore water, but this difference is negligible. Hereafter, we report values 148 as hydraulic conductivities in this paper. We assumed the sediments were homogenous and 149 isotropic.

Boundary conditions for the model domains consisted of a no-flow boundary on the 151 bottom, a specified fluid flux on the landward vertical boundary and a time-variable, combined 152 specified fluid pressure and flux along the surface boundary of the domain (Fig. 2). For sections 153 of the surface boundary that were never inundated by the tide, the boundary condition is no-flow. 154 For areas that were inundated, boundary conditions were specified based on tidal height similarly 
155 as described in Wilson et al., [2006]. Inundated areas were assigned a pressure based on the 156 depth of the overlying water column. When inundated surface nodes had saturations less than 1, 157 a specified flux boundary was applied. If a node along the surface of the domain was exposed 158 and the sediment was fully saturated, a seepage face formed. A theoretical semi-diurnal tide with 159 a period of 12 hours and baseline amplitude of $1 \mathrm{~m}$ was used. Tidal amplitude was one of the 160 parameters systematically tested in the experiment. Mean water level for the tidal signal was set 161 to be $0 \mathrm{~m}$.

Model domain dimensions were chosen to balance the need for accurate simulation 163 results and computational efficiency. The boundary source of freshwater was positioned far 164 enough away from the intertidal zone to avoid artifacts and boundary effects. The model was 165 extended far enough offshore that the seaward no flow boundary did not interfere with 166 development of the freshwater-saltwater interface. Final model domains ranged from $300-800$ $167 \mathrm{~m}$ in length by $32 \mathrm{~m}$ deep. Initial conditions were handled by assigning pressure equivalent to a hydraulic head of

$1691 \mathrm{~m}$ throughout the domain. Salinity was handled by assigning all nodes landward of the center of 170 the intertidal zone as 1 part per thousand (ppt), and all nodes seaward as $34 \mathrm{ppt}$ to represent 171 seawater. Initial conditions did not affect the results because all simulations ran until they 172 reached a quasi-steady state. A total of 105 separate simulations were developed for a model 173 time of approximately 548 days. Time steps of 10 min were required to effectively capture 174 hydraulic responses to tidal fluctuations.

175 We explored three measures to rank the strength of the upper saline plume in each 176 simulation. The first was a saline plume salinity gradient (SPSG) measured parallel to the upper 
177 boundary of the model from the center of the upper saline plume on the beach surface to the 178 center of the freshwater tube directly seaward (Fig. 1). The SPSG measurement was made at 179 high tide in every model. Both concentration measurements were made at a depth of $1 \mathrm{~m}$ below 180 land surface, representative of a typical piezometer depth in a beach. This depth also reaches 181 below the zone of shallow mixing induced by waves, which were not considered in our 182 simulations. Calculated this way, the SPSG is easily measureable in field settings. We classified 183 "strong" upper saline plumes as having an SPSG greater than $0.15 \mathrm{ppt} / \mathrm{m}$. "Moderate" upper 184 saline plumes had SPSGs between 0.05 and $0.015 \mathrm{ppt} / \mathrm{m}$, and "weak" upper saline plumes had 185 SPSGs lower than $0.05 \mathrm{ppt} / \mathrm{m}$. A complete lack of an upper saline plume was characterized by an 186 SPSG of 0.

We also calculated TDR and DDR for each simulation, as indications of the volume of 188 water that circulated through the beach. To do so, we calculated tidally driven $\left(\mathrm{Q}_{\mathrm{t}}\right)$ and density 189 driven $\left(\mathrm{Q}_{\mathrm{d}}\right)$ recharge rates in the beach aquifer. We defined $\mathrm{Q}_{\mathrm{t}}$ to be all recharge into the beach 190 above the elevation of low tide and $\mathrm{Q}_{\mathrm{d}}$ to be all recharge at elevations lower than that of low tide. 191 These volumetric fluxes where then divided by the rate of fresh water inflow into the model $\left(\mathrm{Q}_{\mathrm{f}}\right)$ 192 and multiplied by 100 to yield nondimensional TDR and DDR. Robinson et al. (2007a) 193 segregated TDR from DDR by the location of the freshwater discharge tube, which corresponds 194 very closely to the elevation of low tide. We did not use the location of the freshwater discharge 195 tube specifically because it did not exist in every simulation. This approach does not measure 196 density-driven recirculation that occurs when density gradients center around the high tide line, 197 but our purpose was to identify the presence and importance of the freshwater tube.

We note that the saline plume salinity gradient, as defined above, provides an indication 199 of whether an upper saline plume exists at a site, as determined by whether an identifiable 
200 freshwater tube is present. TDR and DDR are instead measures of how much water flows

201 through the system. DDR has the potential to co-vary with the measured SPSG because higher

202 salinity gradients in the upper saline plume may correspond to larger density gradients

203 surrounding the lower salt water wedge. These gradients in turn drive DDR. TDR is clearly

204 required if an upper saline plume is to form, but the relationship between TDR and strong upper

205 saline plumes is not well defined.

207 3. Results

Our baseline simulation was used as a point of comparison for subsequent simulations due to

210 the moderate parameter values used and upper saline plume that developed (Fig. 3a-e). The

211 maximum pore water salinity in the upper saline plume was approximately $33 \mathrm{ppt}$, and the

212 minimum salinity of pore water discharging from the adjacent freshwater tube was

213 approximately 29 ppt. In this simulation, the SPSG between the center of the upper saline plume

214 and the adjacent freshwater tube was $0.11 \mathrm{ppt} / \mathrm{m}$. This indicates a moderate saline plume. TDR

215 for the baseline simulation was 55.9\% and DDR was 9.6\%. Groundwater flow velocities in the

216 intertidal zone were greatest during low tides and least during flood tides (Fig. 3b-e). Seawater

217 circulated through the beach aquifer on each tidal cycle, where it mixed with fresher pore water.

218 In general, saline pore water infiltrated into the aquifer during high tides and was discharged to

219 the coastal ocean during low tides. Groundwater discharge from the beach aquifer was focused at

220 the level of the tide as it moved across the beach. The maximum rate of discharge over a tidal

221 cycle occurred directly landward of the lowest extent of the tide on the beach (low tide). 
All 105 simulations showed that a freshwater-saltwater interface developed below the

223 intertidal zone, but the width and configuration of the salinity distribution was highly variable.

224 The maximum salinity of the upper saline plume ranged from 28 to $34 \mathrm{ppt}$ in each model, and the

225 salinity of pore water discharging from the freshwater tube varied from 6 ppt to 34 ppt. For a

226 hydraulic conductivity of $10 \mathrm{~m} / \mathrm{d}$, the maximum measured rate for TDR was $85.33 \%$ and the

227 minimum was $6.05 \%$. The maximum rate for DDR was $43.77 \%$ and the minimum was $1.56 \%$.

228 The salinity distribution remained stable throughout the tidal cycle. The configuration of the

229 salinity distribution of the freshwater-saltwater interface was also highly variable between

230 separate simulations; some models contained an upper saline plume, while others showed only a

231 lower salt wedge.

The slope of the intertidal zone of the beach was found to be a major controlling factor

233 for the development of an upper saline plume and for flow through the beach in general. For the

234 cases simulated, higher beach slopes supported a greater SPSG, greater DDR and greater TDR

235 than lower beach slopes (Table 2). When beach slopes fell below 0.05, the upper saline plume

236 weakened significantly and could not support density gradients high enough to drive significant

237 rates of DDR. This relationship is illustrated very clearly in a subset of simulations where tidally

238 averaged flow rates are compared directly to the subsequent salinity configuration (Fig. 4).

239 Tidally average flow rates decrease in magnitude with decreasing beach slope. Beach slopes

240 above or equal to 0.05 had larger hydraulic gradients, allowing greater discharge rates from the

241 beach, which in turn allowed greater rates of TDR. No upper saline plume formed in any beach

242 with a slope of 0.01 except when the hydraulic conductivity was set higher to $100 \mathrm{~m} / \mathrm{d}$.

Density-driven infiltration into the beach aquifer was found to increase with increasing

244 SPSG in all simulations (Fig 5a). Higher groundwater salinity gradients between the saline 
245 plume and freshwater tube, and therefore more distinct upper saline plumes, drove greater rates

246 of density-driven convection under the beach. Rates of density-driven recharge into the beach

247 aquifer could therefore be used as an indicator of the strength of the upper saline plume in a

248 beach, but we ultimately chose to report measured SPSGs because they can be readily measured

249 in the field. Infiltration rates into the beach aquifer are tedious and difficult to measure in a real

250 beach.

Varying the hydraulic conductivity shifted the range of beach slopes that could sustain an

252 upper saline plume (Fig. 6a). A hydraulic conductivity of $100 \mathrm{~m} / \mathrm{d}$ allowed the formation of an

253 upper saline plume only in beaches with slopes of 0.025 and 0.01 . In beaches with slopes greater

254 than 0.025 , only a lower salt wedge developed. Only very low-slope beaches allowed a weak

255 upper saline plume at this hydraulic conductivity. A hydraulic conductivity of $10 \mathrm{~m} / \mathrm{d}$ led to the

256 strongest upper saline plumes (Fig. 6a). With this hydraulic conductivity, seawater could

257 effectively infiltrate the subsurface during inundation, and tidally-averaged flow rates through

258 the beach were high enough to sustain an upper saline plume. No upper saline plumes formed in

259 any beach with hydraulic conductivities less than or equal to $1 \mathrm{~m} / \mathrm{d}$ because tidally-averaged flow

260 rates through the beach were too low. TDR and DDR rates were proportional to hydraulic

261 conductivity because greater volumes of water moved through the beach aquifers with higher

262 hydraulic conductivities (Supp. 1a; 2a).

We also varied the flux of fresh groundwater from the landward boundary into the

264 models. The magnitude of fresh groundwater input into the model strongly influenced the

265 development of the upper saline plume and associated SPSG (Fig. 6b). SPSGs were very low for

266 inflow velocities of $\sim 10^{-8}$ to $10^{-6} \mathrm{~m} / \mathrm{s}$, increasing significantly for velocities of $7.6 \times 10^{-6} \mathrm{~m} / \mathrm{s}$ and

267 greater (Fig. 6b). A greater inflow of fresh pore water caused a sharper salinity gradient to 
268 develop at the freshwater-saltwater interface because the salinity of water discharging through

269 the freshwater tube was lower. For a given freshwater flow, SPSGs generally increased with

270 increasing beach slope. No upper saline plumes formed in beaches with a slope of 0.01

271 regardless of the magnitude of fresh groundwater input. Rates of TDR decreased with higher

272 fluxes of terrestrially derived freshwater (Supp. 1b). DDR increased with higher fluxes of

273 terrestrially derived freshwater for beach slopes greater than 0.01 (Supp. 2b).

We found that tidal amplitude exhibited significant control on the strength of the upper

275 saline plume. For beaches with slopes of 0.05 to 0.1 , the SPSG and tidal amplitude were

276 approximately inversely proportional (Fig. 6c). Higher tidal amplitudes caused inundation of

277 larger areas of the beach, spreading out the upper saline plume and decreasing the SPSG. The

278 simulations with an intertidal zone slope of 0.025 were particularly sensitive to tidal amplitude;

279 for this slope, the upper saline plume failed to form for tidal amplitudes less than or equal to 0.75

$280 \mathrm{~m}$. For tidal amplitudes of $1 \mathrm{~m}$ or greater, the associated SPSG was relatively constant. As

281 previously indicated, no upper saline plumes formed in beaches with a slope of 0.01 regardless

282 of the tidal amplitude. Rates of TDR increased with increasing tidal amplitude as larger areas of

283 the beach were inundated by the tide (Supp. 1c). Rates of DDR increased with decreasing tidal

284 amplitude because stronger salinity gradients developed between the saline plume and adjacent

285 freshwater tube (Supp. 2c).

Dispersivity was also found to be a major controlling factor for the development of an

287 upper saline plume in a beach. Transverse dispersivity was a much more significant control on

288 salinity configuration than longitudinal dispersivity because the salinity gradients developed

289 perpendicular to the dominant flow direction in the beach (vertical). For beaches with slopes of

2900.05 or greater, small dispersivities increased the SPSG and allowed more distinct upper saline 
291 plumes to form (Fig. 6d). For beaches with lower slopes, small dispersivities prevented the

292 formation of an upper saline plume. This occurred because a minimum level of mixing was

293 required in the aquifer to allow the formation of an upper saline plume. Varying dispersivities in

294 a beach with a slope of 0.01 did not produce an upper saline plume. Rates of TDR were

295 relatively constant with increasing dispersivities while rates of DDR decreased with increasing

296 dispersivities (Supp. 1d; 2d).

\section{4. Discussion}

Our results suggest that upper saline plumes do not form in all beaches. We found that the

most significant controls on the development of an upper saline plume in a beach were hydraulic development of an upper saline plume in the subterranean estuary. exposed beach (Bascom, 1959):

$$
\beta=0.0045 e^{5.3612 d}
$$

307 where $\beta$ is the beach slope and $d$ is the median grain size of the beach sediments. The grain size 308 of sediments deposited on a beach is controlled by the wave energy in the coastal ocean.

309 Sediments with a larger median grain size can support a steeper slope while sediments with 310 smaller grain sizes build shallower slopes. Due to the relationship between grain size and beach 311 slope, grain size is also correlated to the development of an upper saline plume. Wilson et al. 312 (2008) showed that the median grain size of coastal sediments is also a good indicator of 
313 permeability. Sediments with larger grain sizes had higher permeability values in both near-shore 314 and continental shelf samples and can be fit by the following equation:

$$
k=4 \times 10^{-10} d^{1.6}
$$

316 where $k$ is permeability and $d$ is the median grain size of the sediments.

317 Due to the correlation between sediment grain size and both permeability and beach slope, grain 318 size of beach sediments is also indirectly correlated to the presence/absence of an upper saline 319 plume.

The link between grain size, beach slope and permeability indicates a very specific set of 321 conditions required to have an upper saline plume in a beach. As the median grain size in a beach 322 increases, the permeability and slope of the intertidal zone increase (Fig. 7). Steeper slopes in 323 the intertidal zone support more distinct upper saline plumes, but this is balanced by the fact that 324 permeability values also increase and flushing rates are more rapid. Beaches with shallow slopes 325 have finer sediments with lower permeability values, further reducing the potential for 326 developing an upper saline plume. works: Waquoit Bay, Massachusetts (Abarca et al., 2013), Cape Henlopen (Heiss and Michael, 329 2014) and Moreton Island, Australia (Robinson et al., 2006a and Kuan et al., 2012). All three of 330 these beaches have intertidal zone slopes of approximately 0.09 or greater. Bascom (1959) 331 compiled approximately 500 profiles from 40 beaches on the Pacific Coast of the United States.

332 Beach slopes in the intertidal zone ranged from 0.25 to 0.01. McLachlan and Dorvlo (2005) 333 categorized 161 sandy beach transects from a wide variety of locations worldwide and found that 334 beach slopes range from approximately 0.2 to 0.0125 , with an average beach slope of 0.037 . Our 335 model results predict that more prominent upper saline plumes develop and persist in beaches 
with greater slopes. Upper saline plumes weakened significantly in beaches with intertidal zone

337 slopes less than 0.5 . This suggests that a large portion of the world's beaches do not exhibit a

338 strong, persistent upper saline plume.

339 We can now consider the relationship between the presence of an upper saline plume and 340 the volume of submarine groundwater discharge. Strong upper saline plumes had high rates of

341 TDR and DDR. Our model results indicate that increasing values of $\varepsilon$ (lower beach slopes) lead 342 to lower SPSGs in the beach, representative of weak or absent upper saline plumes (Fig. 8a).

343 Robinson et al. (2007a) showed that increasing values of $\varepsilon$ led to increasing rates of TDR for 344 steeper beaches ( 0.1 to 0.4$)$, and TDR began to behave asymptotically for moderate beach slopes 345 (0.067). Our results show that TDR (Fig. 8b) and DDR (Fig. 8c) drop off significantly for 346 moderate to low slope beaches (0.05 to 0.01$)$. As the beach slope approached the horizontal 347 (increasing values of $\varepsilon$ ), the hydraulic gradient that drives seawater infiltration into the intertidal 348 zone decreased. These relationships indicate that the formation of a stable upper saline plume 349 occurs in beaches where TDR is sufficient to supply the beach with seawater each tidal cycle, 350 and where DDR is high due to strong convective flow associated with a strong salinity gradient. 351 Higher SPSGs form in beaches with higher slopes. Upper saline plumes cannot persist in the 352 subterranean estuary through the tidal cycle when rates of TDR and DDR are low, as they are in 353 beaches with low slopes.

354 Controls on the formation of an upper saline plume can be further explored by examining 355 the relationship between advection and dispersion in the beach aquifer. We can quantify these 356 relationships by using the Peclet number:

$$
P_{e}=\frac{v_{x} L}{D}=\frac{L}{\alpha_{T}}
$$


358 where $v_{x}$ is groundwater velocity, $L$ is the length scale of interest, $D$ the dispersion coefficient

359 and $\alpha_{T}$ is transverse dispersivity. Substituting the width of the intertidal zone (equation 1) for $L$

360 yields:

$$
P_{e}=\frac{L}{\alpha_{T}}=\frac{A \cot \beta}{\alpha_{T}}
$$

362

363

364 377 values, thereby allowing the development of an upper saline plume. Inducing the development

where $A$ is tidal amplitude and $\beta$ is the slope of the beach. The most significant SPSGs, and therefore the strongest upper saline plumes, occurred with relatively low $(<15)$ Peclet numbers (Fig. 8d). This relationship suggests that upper saline plumes form when advection is moderate with respect to dispersion. When advection rates are high with respect to dispersion, SPSGs decrease to 0 . However, upper saline plumes will not develop when dispersive transfer begins to dominate over advective transfer. In order for an upper saline plume to develop, advection through the subterranean aquifer is necessary.

Anthropogenic modifications to beaches have the potential to alter groundwater flow and exchange. Coastal engineering and beach nourishment are currently active strategies to combat sediment loss due to erosion and longshore drift in beaches. A common practice to reduce sediment loss from beaches with high rates of erosion is to build up the beach face with homogenous sands with larger grain sizes (Delft Hydraulics, 1987; Davidson et al., 1992; California Department of Boating and Waterways, 2002). The larger grain size means that less sediment can be entrained by the local waves due to the increased grain size, leading to a net decrease in erosion. Beach nourishment could artificially increase beach slopes and permeability of an upper saline plume in a beach could lead to increased rates of nutrient remineralization and potential export to the coastal ocean. If a beach managed in such a way is within a coastal zone that is already experiencing anthropogenic eutrophication and algal blooms, increased nutrient 
381 export to sensitive coastal waters could further reduce water quality. Coastal managers should

382 consider the potential effects of beach modifications on groundwater systems and the fertility of

383 the local coastal ocean.

384 It is important to consider that real beaches exhibit variability in sediment grain size and 385 therefore permeability and beach slope. Some beaches have multiple slope breaks along their 386 profiles where small, localized upper saline plumes could develop. Beach profiles are also 387 dynamic with respect to season, experiencing increased rates of erosion during winter months 388 and increased sediment accretion during summer (Aubrey, 1979). Beaches on transgressive 389 barrier islands can have relic marsh muds buried in the subsurface (Anderson et al., 2000), 390 leading to complex stratigraphy and permeability anisotropy. Although quantifying these effects 391 is beyond the scope of the current paper, these effects clearly warrant future investigation. 392 In our simulations, we used a simulated tidal signal to represent tidal forcing. Real tidal 393 signals that include variations in mean water level, sea level and lunar cycles such as spring-neap 394 tides are likely to yield variable results. Abarca et al. (2013) showed that real tides, even with 395 small tidal amplitudes, can create significant variability in fluxes in a beach aquifer. Spring-neap 396 tidal cycles also cause the upper saline plume to expand and contract in response to changes in 397 tidal amplitude (Robinson et al., 2007b). Field studies with a goal of delineating an upper saline 398 plume in a beach should span an entire lunar tidal cycle to capture the variability in both 399 groundwater fluxes and salinity distribution.

400 TDR and DDR rates are important data for understanding SGD, but are difficult to measure 401 in the field and often require computational methods to estimate. Salinity distribution in a beach 402 aquifer is a useful indicator of groundwater flow dynamics. Measuring the salinity of 403 groundwater is simple, and often the first step in identifying the configuration of the freshwater- 
404 saltwater interface in a beach. A saline plume salinity gradient can be measured by installing

405 piezometers in the intertidal zone of a beach, near the average elevation of low tide and mean sea

406 level. By also measuring the median grain size of beach sediments, the beach slope, the tidal

407 amplitude and elevation of mean sea level at a field site, it is then possible to estimate general

408 rates of TDR and DDR. For example, density-driven recirculation rates are related to the strength

409 of the measured SPSG between the saline plume and the freshwater discharge tube, located near

410 the average low-tide line. The salinity gradient increases with increasing beach slope. In general,

411 the fresher the water in the discharge tube, the greater the rates of DDR in the beach. TDR rates

412 are largely dependent on the slope of the beach, tidal amplitude and permeability. Beach slopes

413 between 0.5 and 0.1 had the greatest rates of TDR, while rates decreased significantly for lower

414 beach slopes where the hydraulic gradient across the ocean-aquifer interface was low. When both

415 TDR and DDR rates are low, there will be no distinct upper saline plume, and the SPSG in the

416 beach will be close to 0 . Flow velocities through the beach are slowest in beaches with shallow

417 slopes.

418

419

\section{Conclusion}

Our results suggest that the upper saline plume may be an uncommon phenomenon that

422 only occurs in beaches with the appropriate combination of beach slope, hydraulic conductivity

423 and fresh groundwater flux into the beach. The development of an upper saline plume under a

424 beach requires high rates of TDR which create strong salinity gradients and therefore high rates

425 of DDR. Steeper beach slopes supported higher SPSGs in the beach aquifer and therefore had

426 more distinct upper saline plumes. No upper saline plumes formed in any simulations when the 
427 hydraulic conductivity was below $10 \mathrm{~m} / \mathrm{d}$. Sufficient volumes of seawater could not infiltrate the

428 beach aquifer during high tide. Upper saline plumes were less distinct for hydraulic

429 conductivities greater than or equal to $100 \mathrm{~m} / \mathrm{d}$ because pore water was flushed through the

430 beach too rapidly, leading to the development of a lower salt wedge only. Increasing the fresh

431 groundwater flux into the model decreased the salinity of groundwater that discharged seaward

432 of the upper saline plume, increasing the SPSG.

Dispersivity also had an important effect on the distribution of salinity in the pore water.

434 Lower transverse dispersivities allowed higher SPSGs to develop in the simulations. Prior

435 studies of groundwater flow and salinity in beaches have used small dispersivities (Robinson et

436 al., 2007a). We found that the upper saline plume became much less distinct when larger

437 dispersivities were used, because more mixing occurred in the simulations. Real beaches are

438 highly mixed environments, with waves, heterogeneous sediments and geologic layering.

439 Longitudinal dispersivity can vary by an order of 2 within a single field site, adding additional

440 complications to simulating field data of salinity distribution (Gelhar et al., 1992). The

441 appropriate magnitude of dispersivities to be used in modeling groundwater in beaches remains

442 unclear (Smith, 2004).

The median grain size of beach sediments has the potential to be an indicator of whether

444 or not a beach will have an upper saline plume because of the correlations between grain size and

445 both beach slope and permeability. In order for a beach to contain a prominent upper saline

446 plume, the sediment grain size must allow a steep beach face to develop with permeability values

447 high enough to allow sufficient infiltration of seawater but not too high to prevent strong salinity

448 gradients from developing. Because of this relationship, wide, gently sloping beaches with fine

449 grained sands will not support distinct upper saline plumes. 
Finally, the observation of the presence or absence of an upper saline plume in a beach is

451 important because it allows a conceptual model to be developed with respect to submarine

452 groundwater discharge and seawater recirculation. If a strong upper saline plume is identified in

453 a beach, it can be determined that rates of DDR are high. The presence of a moderate or weak

454 upper saline plume indicates that rates of DDR are lower in that beach. A beach with no upper

455 saline plume will still undergo DDR across the lower salt wedge, but the rates will be

456 significantly lower than in beaches with a USP. TDR is more difficult to determine from the

457 configuration of the salinity distribution alone because TDR is dependent on beach slope, tidal

458 amplitude and inland fresh groundwater head. TDR is highest in beaches with moderate to steep

459 slopes (0.05 to 0.1$)$, large tidal amplitudes and low terrestrial groundwater flux. These types of

460 beaches exhibit moderate/weak upper saline plumes because the SPSG decreases with increasing

461 tidal amplitude and decreasing terrestrial groundwater flux. Therefore, beaches with slopes

462 between 0.05 and 0.1 and no upper saline plume have the highest rates of TDR. Beaches with

463 slopes in this range that have an upper saline plume will likely have moderate rates of TDR. Any

464 beaches with slopes less than 0.05 will have the lowest rates of TDR. High rates of circulation

465 through the beach aquifer are important because they could lead to higher rates of geochemical

466 exchange and transformation. By identifying the salinity configuration in a beach aquifer,

467 powerful hypotheses about flow and geochemical exchange can begin to be developed from a

468 simple measure. 
472 Acknowledgements. We thank C. Robinson, R. Corbett and three anonymous reviewers for their 473 helpful insight which benefitted this work. We thank A. Hughes for her assistance with modeling 474 software. This material is based upon work supported by the National Science Foundation under 475 grant 0711301 . Any opinions, findings, and conclusions or recommendations expressed in this 476 material are those of the author(s) and do not necessarily reflect the views of the National 477 Science Foundation. All data used in this study are available upon request from the 478 corresponding authors.

479

\section{References}

Abarca, E., H. Karam, H.F. Hemond, C.F. Harvey. (2013). Transient groundwater dynamics in a coastal aquifer: The effects of tides, the lunar cycle, and the beach profile. Water Resources Research, 49:2473-2488.

Anderson, W.P. Jr.; D.G. Evans; S.W. Snyder. (2000). The effects of Holocene barrier-island evolution on

Aubrey, D.G. (1979). Seasonal patterns of onshore/offshore sediment movement. J. Geophys. Res.,

Bascom, W. N. (1959). The relationship between sand grain size and beach-face slope. Am. Geophys. 
504

505

506

507

508

509

510

511

512

513

514

515

516

517

518

519

520

521

522

523

524

525

526

527

528

529

530

531

532

533

534

535

Brown, A.C., A. McLachlan. (2002). Sandy shore ecosystems and the threats facing them: some predictions for the year 2025. Environmental Conservation, 62-77.

Buddemeier, R. (1996). Groundwater flux to the ocean: definitions, data, applications, uncertainties. In Buddemeier, R.W. (ed.), Groundwater Discharge in Coastal Zone: Proceedings of an International Symposium. LOICZ Reports and Studies No. 8, LOICZ, Texel, The Netherlands, 16-21.

Burnett, W. C. (2001). Measurement and significance of the direct discharge of groundwater into the coastal zone. Journal of Sea Research, 109-116.

Burnett, W. C., Bokuniewicz, H., \& Huettel, M. (2003). Groundwater and pore water inputs to the coastal zone. Biogeochemistry, 3-33.

Cartwright, N. (2004). Response of the salt-freshwater interface in a coastal aquifer to a wave-induced groundwater pulse: field observations and modelling. Advances in Water Resources, 297-303.

Charette, M.A. and E. R. Sholkovitz. (2002). Oxidative precipitation of groundwater-derived ferrous iron in the subterranean estuary of a coastal bay. Geophysical Research Letters, 29, 85-1 - 85-4.

Cooper, H. (1959). A Hypothesis Concering the Dynamic Balance of Fresh Water and Salt Water in a Coastal Aquifer. Journal of Geophysical Research, 461-467.

Creed, C. G., \& Bodge, K. R. (2000). Construction Slopes for Beach Nourishment Projects. Journal of Waterway, Port, Coastal and Ocean Engineering, 57-62.

Davidson, A.T.; Nicholls, R.J.; Leatherman, S.P. (1992). Beach nourishment as a coastal management tool: An annotated bibliography on developments associated with the artificial nourishment of beaches. Journal of Coastal Research, 984-1022.

Delft Hydraulics. (1987). Manual on Artificial Beach Nourishment. Delft, The Netherlands: 195p.

Department of Boating and Waterways and State Coastal Conservancy. (2002). California Beach Restoration Study. Sacramento, California.

Galeati, G., G. Gambolati, S.P. Neuman. (1992). Coupled and partially coupled Eulerian-Lagrangian model of freshwater-saltwater mixing. Water Resources Research, 28:149-165.

Gelhar, L.; Welty, C.; Rehfeldt, K. (1992). A critical review of data on field-scale dispersion in aquifers. Water Resources Research, 1955-1974.

Ghyben, B. W. (1889). Nota in verband met de voorgenomen put boring nabij Amsterdam. Koninkl. Inst. Ing. Tijdschr, 21.

Heiss, J.W., H.A. Michael. (2014). Saltwater-freshwater mixing dynamics in a sandy beach aquifer over tidal, spring-neap, and seasonal cycles. Water Resources Research, 50:6747-6766.

Herzberg, A. (1901). Die Wasserversorgung einiger Nordseebader, J. Gasbeleucht. u. Wasserversorg, 44. 
Johannes, R. E. (1980). The ecological significance of the submarine discharge of groundwater. Mar. Ecol. Prog., 365-373.

Kim, G. and D. W. Hwang. (2002). Tidal pumping of groundwater into the coastal ocean revealed from submarine Rn-222 and CH4 monitoring. Geophysical Research Letters, 29(14), 1678.

Krest, J. M., Moore, W. S., \& Gardner, L. R. (2000). Marsh nutrient export supplied by groundwater discharge: Evidence from radium measurements. Global Biogeochemical Cycles, 176-190.

Kuan, W. K., G. Jin, P. Xin, C. Robinson, B. Gibbes, and L. Li. (2012). Tidal influence on seawater intrusion in unconfined coastal aquifers. Water Resources Research, 48:W02502.

Lebbe, L. (1999). Parameter identification in fresh-salt water flow based on borehole resistivities and fresh water head data. Advances in Water Resources, 22(8), 791-806.

Li, L., D.A. Barry, F. Stagnitti, J.Y. Parlange, and D. S. Jeng. (2000). Beach water table fluctuations due to spring-neap tides: Moving boundary effects. Advances in Water Resources, 23:817-824.

Longuet-Higgins, M.S. (1983). Wave set-up, percolation and undertow in the surf zone. Proc. R. Soc. London, Ser. A, 283-291.

McLachlan A., A. Dorvlo. (2005). Global patterns in sandy beach macrobenthic communities. Journal of Coastal Research, 21:674-687.

Moore, W. S. (1996). Large groundwater inputs to coastal waters revealed by 226Ra enrichments. Letters to Nature, 612-614.

Moore, W. S. (1998). The subterranean estuary: a reaction zone of ground water and sea water. Marine Chemistry, 111-125.

Moore, W. S. (2010). A reevaluation of submarine groundwater discharge along the southeastern coast of North America. Global Biogeochemical Cycles, 24:1-9.

Nielsen, P. (1990). Tidal dynamics of the water table in beaches. Water Resources Research, 2127-2134.

Paytan, A., G.G. Shellenbarger, J.H. Street, M.E. Gonneea, K. Davis, M.B. Young and W.S. Moore. (2006). Submarine groundwater discharge: An important source of new inorganic nitrogen to coral reef ecosystems. Limnol. Oceanogr., 51:343-348.

Robinson, C., Gibbes, B., \& Li, L. (3 February 2006). Driving mechanisms for groundwater flow and salt transport in a subterranean estuary. Geophysical Research Letters, 3-6.

Robinson, C.; Li, L.; Barry, D.A. (26 September 2006). Effect of tidal forcing on a subterranean estuary. Advances in Water Resources, 851-865.

Robinson, C.; Li, L. and Prommer, H. (18 July 2007). Tide-induced recirculation across the aquifer-ocean interface. Water Resources Research, 1-14. 
568

569

570

Robinson, C.; Gibbes, B.; Carey, H.; Li, L. (13 September 2007). Salt-freshwater dynamics in a subterranean estuary over a spring-neap tidal cycle. Journal of Geophysical Research, 1-15.

Santos, Isaac R., D. Erler, D. Tait, B.D. Eyre. (2010). Breathing of a coral cay; tracing tidally driven seawater circulation in permeable coral reef sediments. Journal of Geophysical Research.

Santos, Isaac R., W.C. Burnett, S. Misra, I. G. N. A. Suryaputra, J.P. Chanton. (2011). Uranium and barium cycling in a salt wedge subterranean estuary; the influence of tidal pumping. Chemical Geology, 114-123.

Santos, Isaac R; Eyre, Bradley D; Huettel, Markus. (2012). The driving forces of porewater and groundwater flow in permeable coastal sediments: A review. Estuarine, Coastal and Shelf Science, 1-15.

Slomp, CP and Cappellen, PV. (2004). Nutrient inputs to the coastal ocean through submarine groundwater discharge: controls and potential impact. Journal of Hydrology, 64-86.

Sorenson, R.M. (2006). Basic Coastal Engineering, 3rd ed. New York: Springer.

Spiteri, C; Regnier, P; Slomp, CP; Charette, M. (2005). pH-Dependent iron oxide precipitation in a subterranean estuary. . J Geochem Explor, 399-403.

Sun, H. (1997). A two-dimensional analytical solution of groundwater response to tidal loading in an estuary. Water Resources Research, 1429-1435.

Taniguchi, M. and H. Iwakawa. (2004). Submarine groundwater discharge in Osaka Bay, Japan. Limnology, 5:25-32.

Thorn, Paul; Urish, Daniel. (2013). Preliminary Observation of Complex Salt-Fresh Water Mixing in a Beach Aquifer. Ground Water, 145-150.

Uchiyama, Y.; Nadaoka, K.; Rolke, P.; Adachi, K.; Yagi, H. (2000). Submarine groundwater discharge into the sea and associated transport in a sandy beach. Water Resources Research, 1467-1479.

Ullman, William; Chang, Bonnie; Miller, Douglas; Madsen, John. (2002). Groundwater mixing, nutrient diagenesis, and discharges across a sandy beachface, Cape Henlopen, Delware (USA). Estuarine Coastal and Shelf Science, 539-552.

Valiela, Ivan; Costa, Joseph; Foreman, Kenneth; Teal, John M; Howes, Brian L; Aubrey, David G. (1990). Transport of groundwater-borne nutrients from watersheds and their effects on coastal waters. Biogeochemistry, 177-197.

Vandenbohede, A. and L. Lebbe. (2006). Occurence of salt water above fresh water in dynamic equilibrium in coastal groundwater flow systems. Hydrogeology Journal, 14:462-472.

Voss, C. I., \& Provost, A. M. (2002). A model for saturated-unsaturated, variable-density ground-water flow with solute or energy transport. U.S. Geol. Surv. Water Resour. Invest. Rep., 02-4231. 
601 Whiting, G.J. and Childers, D.L. (1989). Subtidal advective flux as a potentially important nutrient input 602 to southeastern U.S.A. saltmarsh estuaries. Estuarine Coastal Shelf Science, 417-431.

603 Wilson, A. M., \& Gardner, L. R. (2006). Tidally driven groundwater flow and solute exchange in a marsh: $604 \quad$ Numerical simulations. Water Resources Research, 1-9.

605 Wilson, A.M.; Huettel, M.; Klein, S. (2008). Grain size and depositional environment as predictors of 606 permeability in coastal marine sands. Estuarine, Coastal and Shelf Science, 193-199.

607 Xin, P.; Robinson, C.; Ling, L.; Barry, D.A.; Bakhtyar, R. (2010). Effects of wave forcing on a subterranean $608 \quad$ estuary. Water Resources Research, 46, W12505, doi:10.1029/2010WR009632.

609 Xue, X, . C. Xie, and J. Wu. (1995). A three-dimensional miscible transport model for seawater intrusion in $610 \quad$ China. Water Resources Research, 31:903-912.

611 


\section{Figures}

Figure 1. (a) Conceptual model of the freshwater-saltwater interface in a beach. After Cooper (1959). (b) The upper saline plume and associated flow paths. After Robinson et al. (2006b). A saline plume salinity gradient (SPSG) was measured from the center of the upper saline plume to the center of the adjacent seepage face in every simulation.

Figure 2. An example of one model domain (slope $=0.05$ ) and the subsequent boundary conditions used for every beach simulation.

Figure 3. (a) Salinity distribution for the baseline simulation. The salinity was normalized so that $1=34 \mathrm{ppt}$. The salinity gradient for this simulation was $0.114 \mathrm{ppt} / \mathrm{m}$. Groundwater velocities for the baseline simulation during (b) high tide, (c) ebb tide, (d) low tide and (e) flood tide. Flow velocities were greatest during low tide and lowest during flood tide. Seawater circulated into the aquifer during rising tide.

Figure 4. Salinity configuration and tide-averaged flow for beaches with intertidal zone slopes of (a) 0.1 , (b) 0.075 , (c) 0.05 , (d) 0.025 and (e) 0.01 . The fresh groundwater flux in these simulations was $7.6 \times 10^{-7} \mathrm{~m} / \mathrm{s}$, hydraulic conductivity was $10 \mathrm{~m} / \mathrm{d}$. The magnitude of the concentration gradient decreased with decreasing beach slope. As beach slope decreased, average flow rate decrease in magnitude, driving lower rates of TDR and DDR through the beach. Table 2 describes values for TDR, DDR, average velocity and salinity gradient for each simulation.

Figure 5. (a) Plot of DDR versus SPSG for simulations with baseline hydraulic conductivity (10 $\mathrm{m} / \mathrm{d}$ ). (b) Subset of simulation results above for a beach slope of 0.1 displaying the relationships between DDR and SPSG for fresh groundwater inflow, dispersivity and tidal amplitude.

Figure 6. Simulation results for tested parameters vs. SPSG for each model domain. (a) Hydraulic conductivity, (b) Fresh groundwater inflow, (c) Tidal amplitude and (d) Transverse dispersivity.

Figure 7. The strength an upper saline plume in a beach, as indicated by SPSG. Open circles represent simulation results. The trend line indicates permeability and beach slope calculated from median grain size $\left(d_{50}\right)$ based on empirical observations (Bascom, 1959; Wilson, 2008). Permeability is likely to vary significantly in beaches, and reasonable values may fall below the line. Only permeability and beach slope were varied in these simulation results; the remaining parameters were equivalent to the baseline simulation. 
Figure 8. (a) The ratio of horizontal shoreline excursion to tidal propagation distance ( $\varepsilon$ ) versus SPSG. (b) TDR vs. $\varepsilon$. (c) DDR vs $\varepsilon$. (d) Peclet number vs. SPSG. Hydraulic conductivity is 10 $\mathrm{m} / \mathrm{d}$ for each case. Intertidal zone slopes $(\beta)$ were $0.1,0.075,0.05,0.025$ and 0.01 . Tidal amplitudes range from 0 to $1.5 \mathrm{~m}$ and transverse dispersivity was $1 \mathrm{~m}$. Note that increasing slopes result in decreasing values of $\varepsilon$. 
Table 1. Parameters used in base model and subsequent beach simulations

\begin{tabular}{|l|l|l|l|l|l|l|}
\hline Beach Slope & 0.01 & 0.025 & $\mathbf{0 . 0 5}^{*}$ & 0.075 & 0.1 & \\
\hline $\begin{array}{l}\text { Tidal } \\
\text { Amplitude } \\
(\mathbf{m})\end{array}$ & 0.25 & 0.5 & 0.75 & $\mathbf{1 . 0}^{*}$ & 1.25 & 1.5 \\
\hline $\begin{array}{l}\text { Dispersivity } \\
(\mathbf{m})\left(\boldsymbol{\alpha}_{\mathbf{L}}, \boldsymbol{\alpha}_{\mathbf{T}}\right)\end{array}$ & $(0.5,0.05)$ & $(1,0.1)$ & $(2.5,0.25)$ & $(5,0.5)$ & $(7.5,0.75)$ & $\mathbf{( 1 0 , 1 )}$ \\
\hline $\begin{array}{l}\text { Freshwater } \\
\text { Flux (m/s) }\end{array}$ & $7.6 \mathrm{E}-08$ & $\mathbf{7 . 6 E - 0 7}$ & $7.6 \mathrm{E}-06$ & $7.6 \mathrm{E}-05$ & $7.6 \mathrm{E}-04$ & \\
\hline $\begin{array}{l}\text { Hydraulic } \\
\text { Conductivity } \\
\text { (m/d) }\end{array}$ & 0.1 & 1 & $\mathbf{1 0}^{*}$ & 100 & & \\
\hline
\end{tabular}

*Baseline simulation parameters.

Table 2. Simulation results specific to Figure 4 (a-e)

\begin{tabular}{|l|l|l|l|l|l|}
\hline Model & $\begin{array}{l}\text { Beach } \\
\text { Slope }\end{array}$ & TDR & DDR & $\begin{array}{l}\text { Max } \\
\text { Average } \\
\text { Velocity } \\
(\mathbf{m} / \mathbf{d})\end{array}$ & $\begin{array}{l}\text { SPSG } \\
\mathbf{( p p t / m )}\end{array}$ \\
\hline a & $\mathbf{0 . 1}$ & $61.92 \%$ & $28.03 \%$ & 1.24 & 0.129 \\
\hline $\mathbf{b}$ & $\mathbf{0 . 0 7 5}$ & $59.49 \%$ & $18.02 \%$ & 1.14 & 0.122 \\
\hline $\mathbf{c}$ & $\mathbf{0 . 0 5}$ & $55.86 \%$ & $9.56 \%$ & 0.784 & 0.114 \\
\hline $\mathbf{d}$ & $\mathbf{0 . 0 2 5}$ & $42.09 \%$ & $3.20 \%$ & 0.411 & 0.039 \\
\hline e & $\mathbf{0 . 0 1}$ & $16.18 \%$ & $2.50 \%$ & 0.253 & 0.0 \\
\hline
\end{tabular}


A)

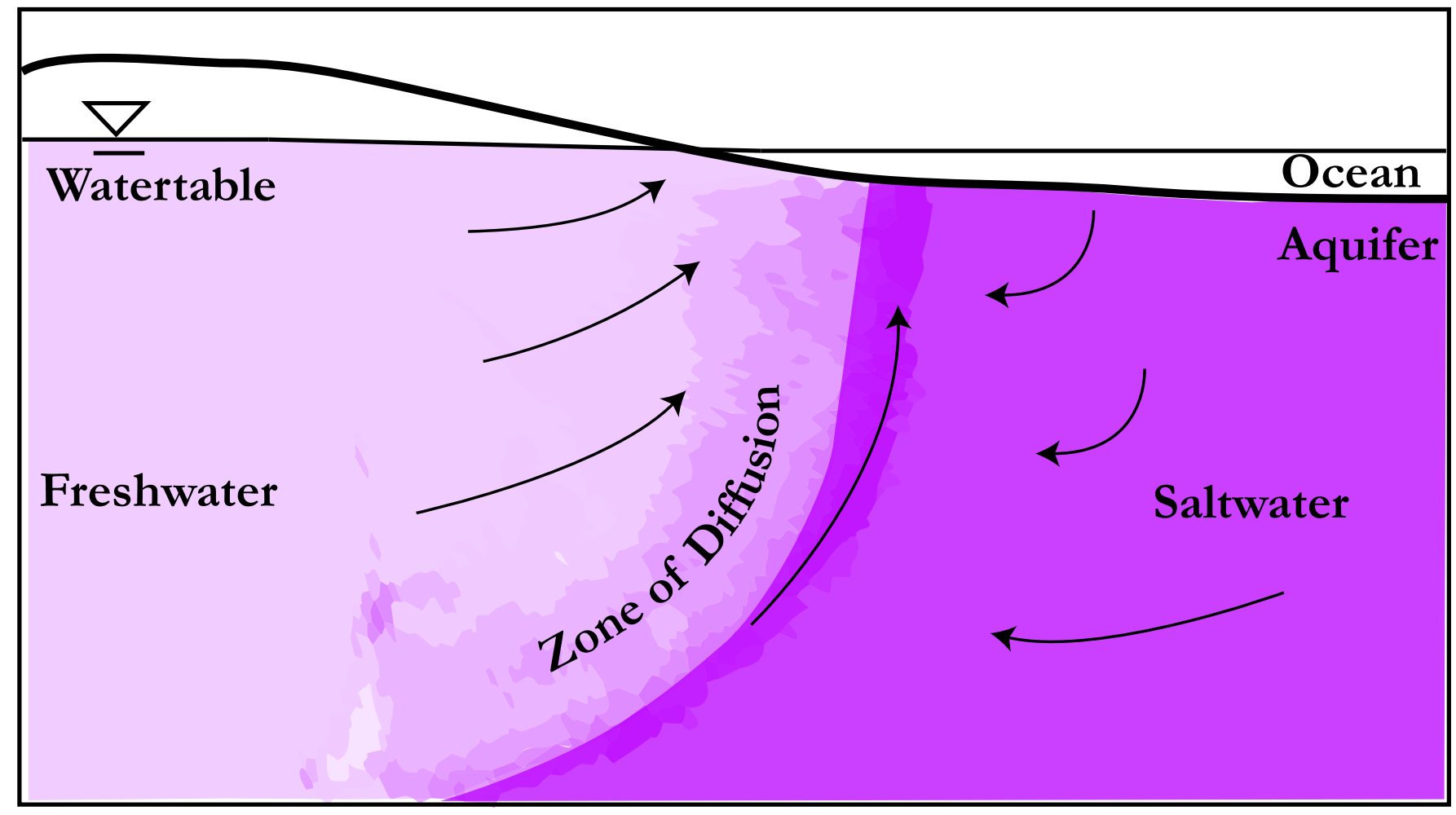

B)

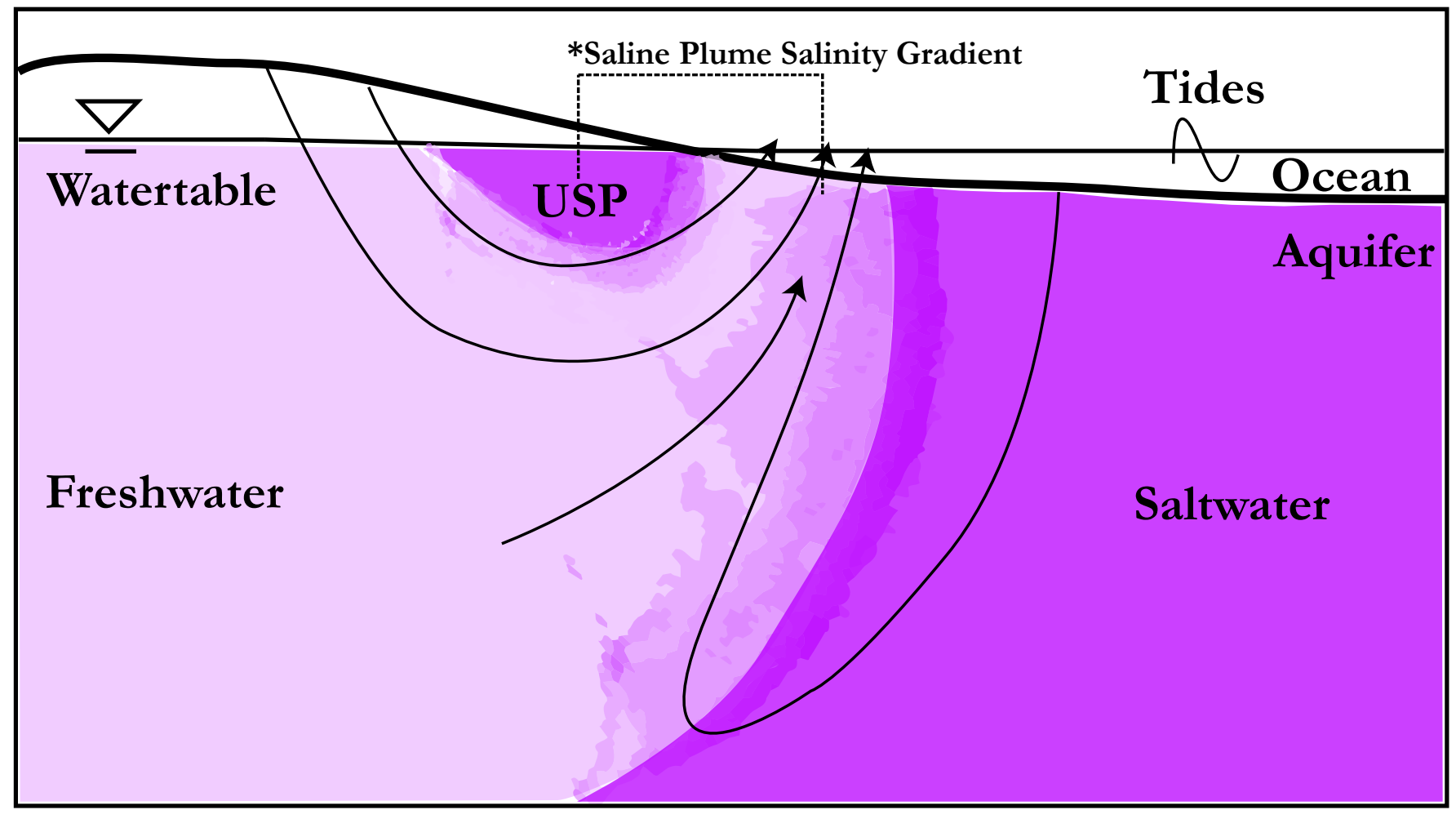

Figure 1 


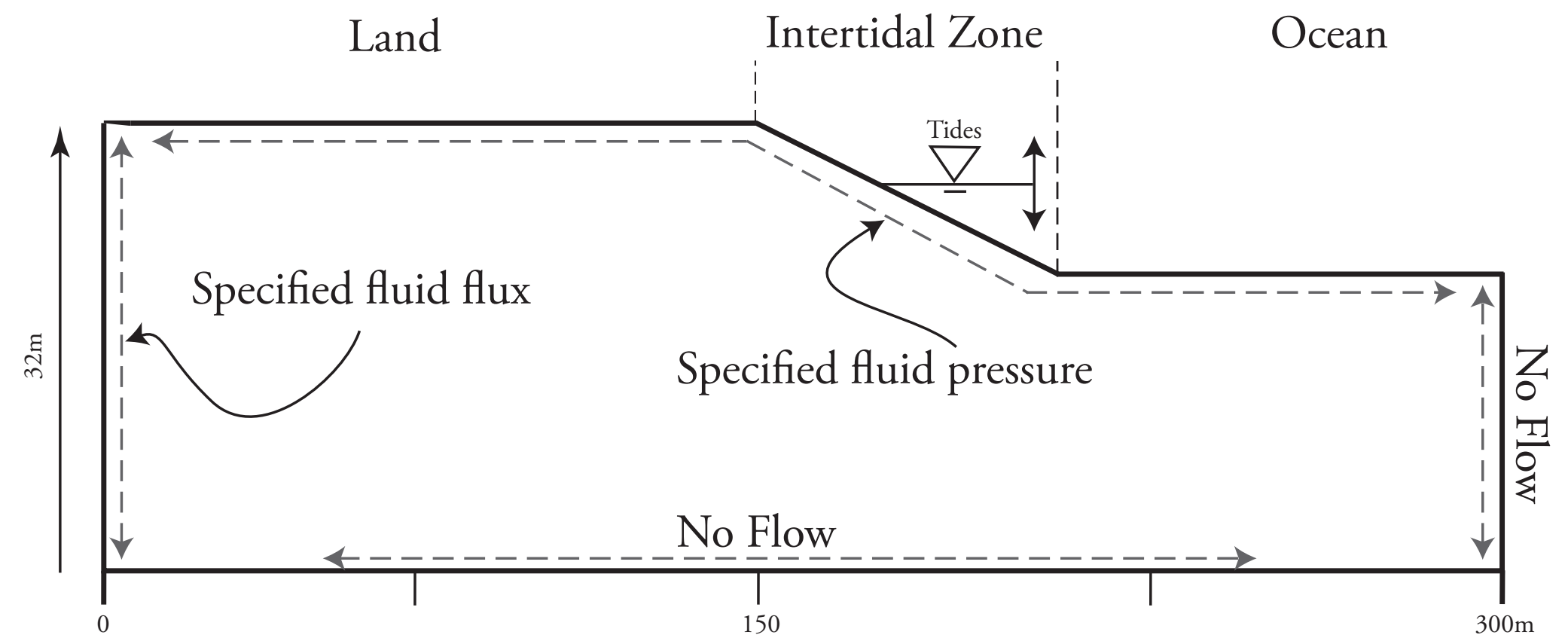

Figure 2 


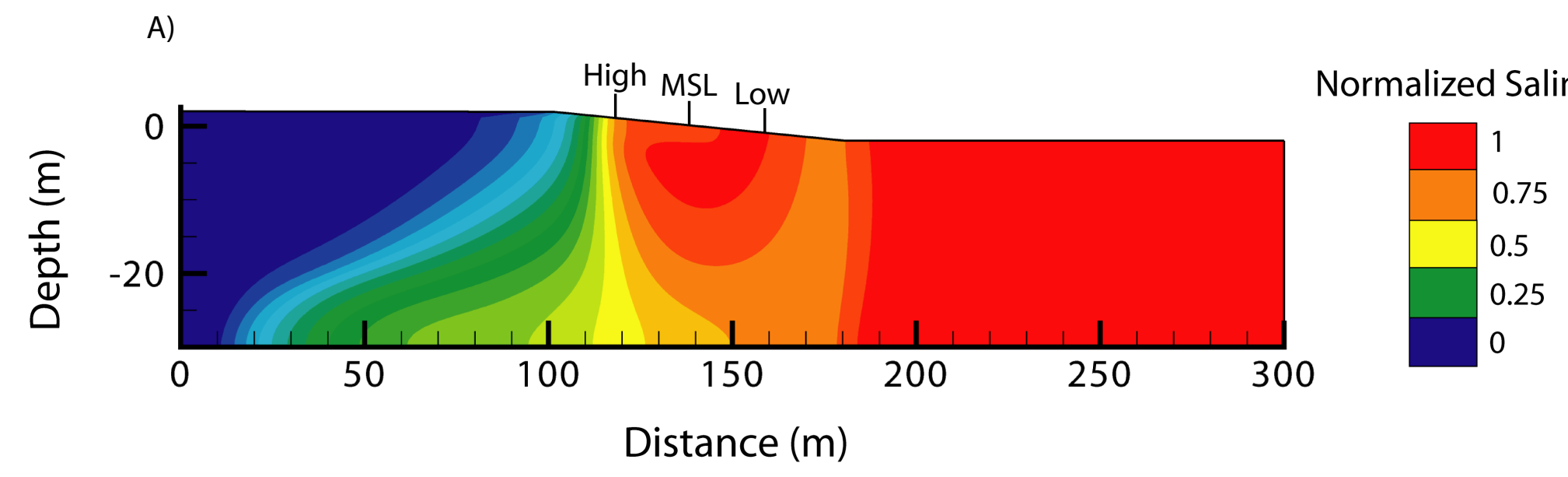

B)

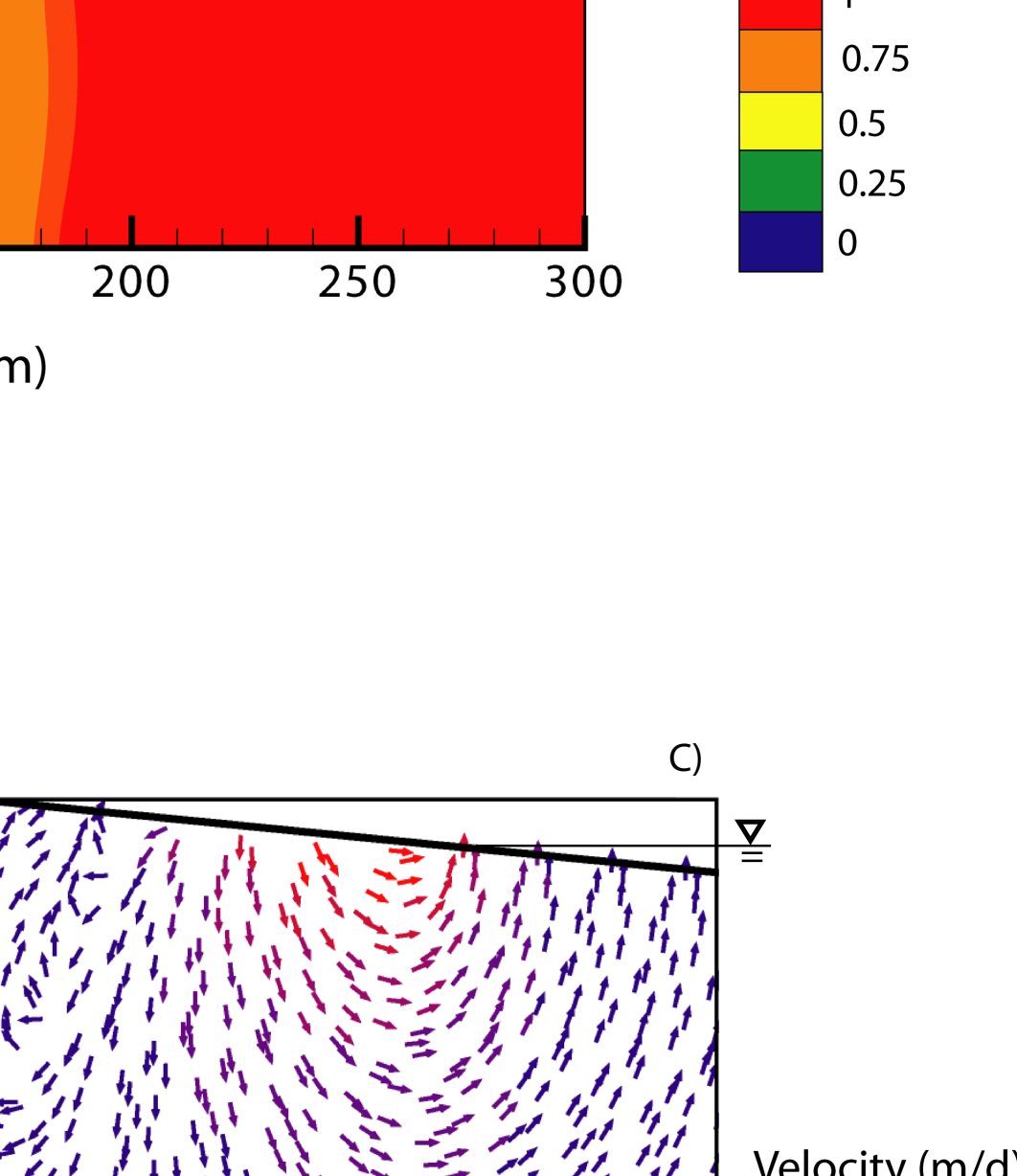

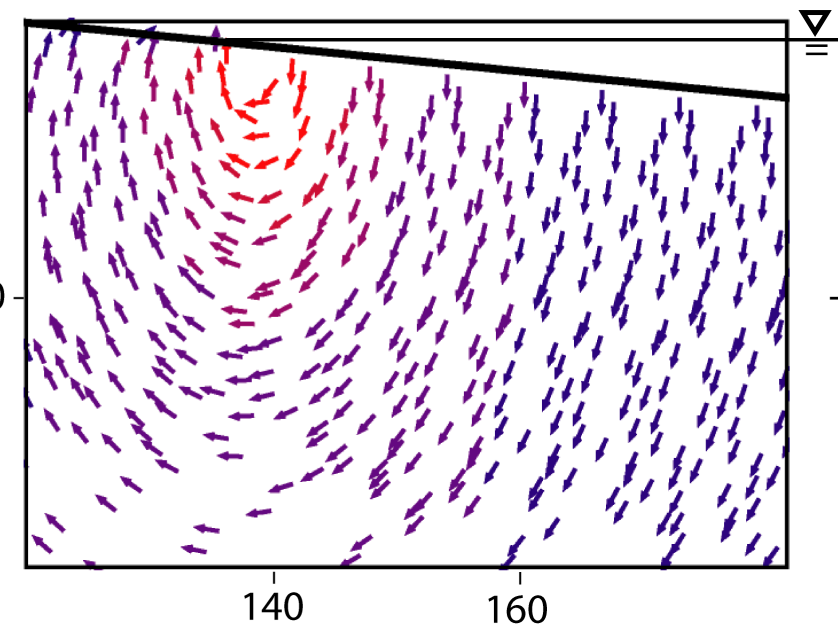

D)

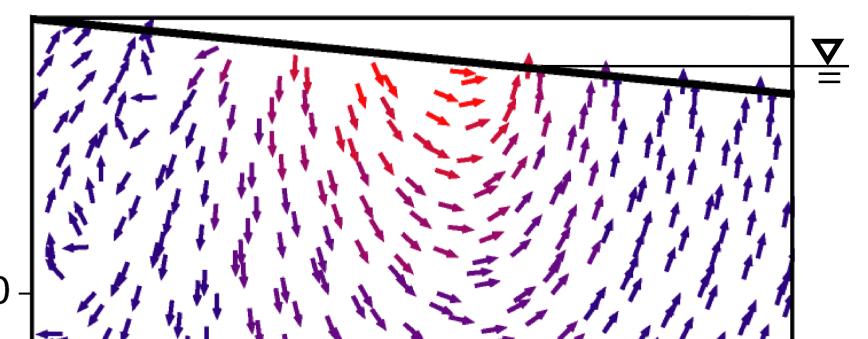

(m)

-

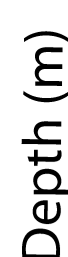
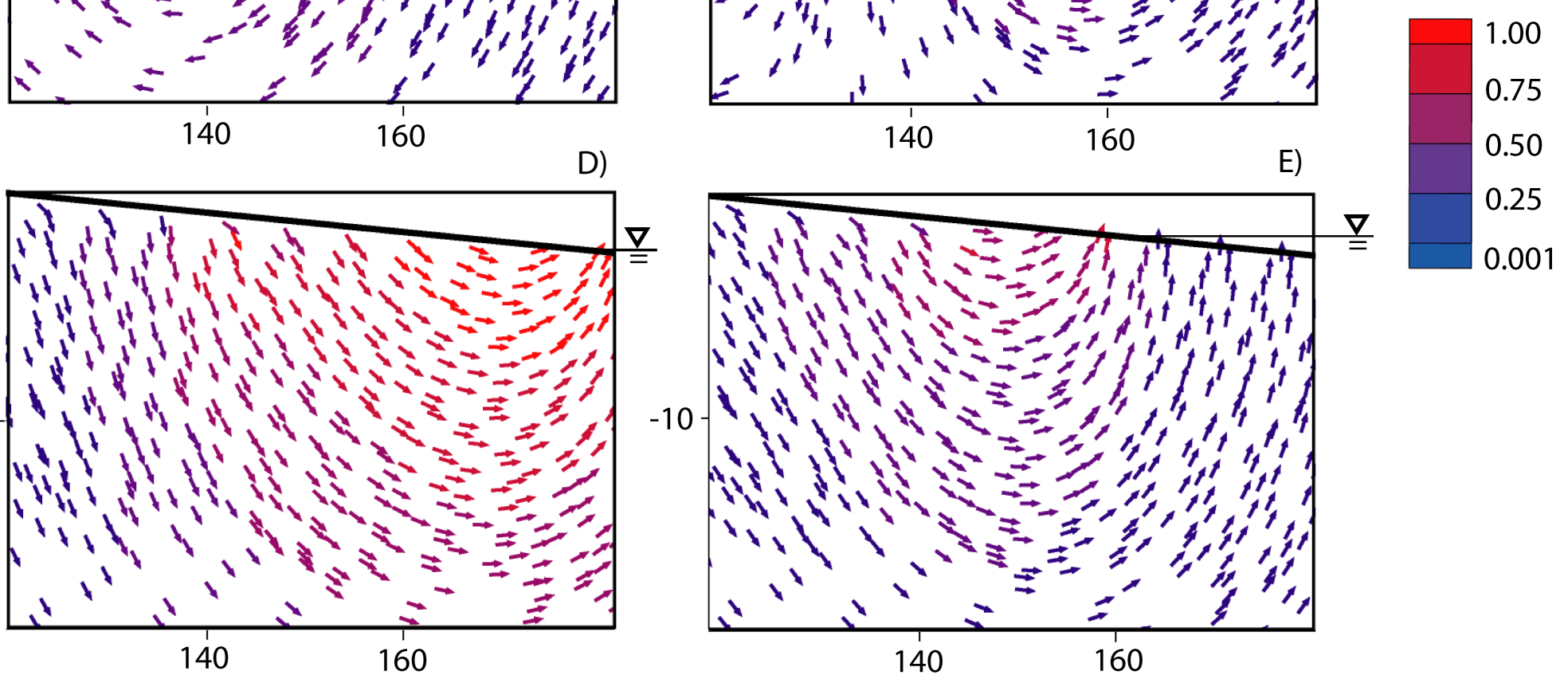

0.001

Distance (m) 

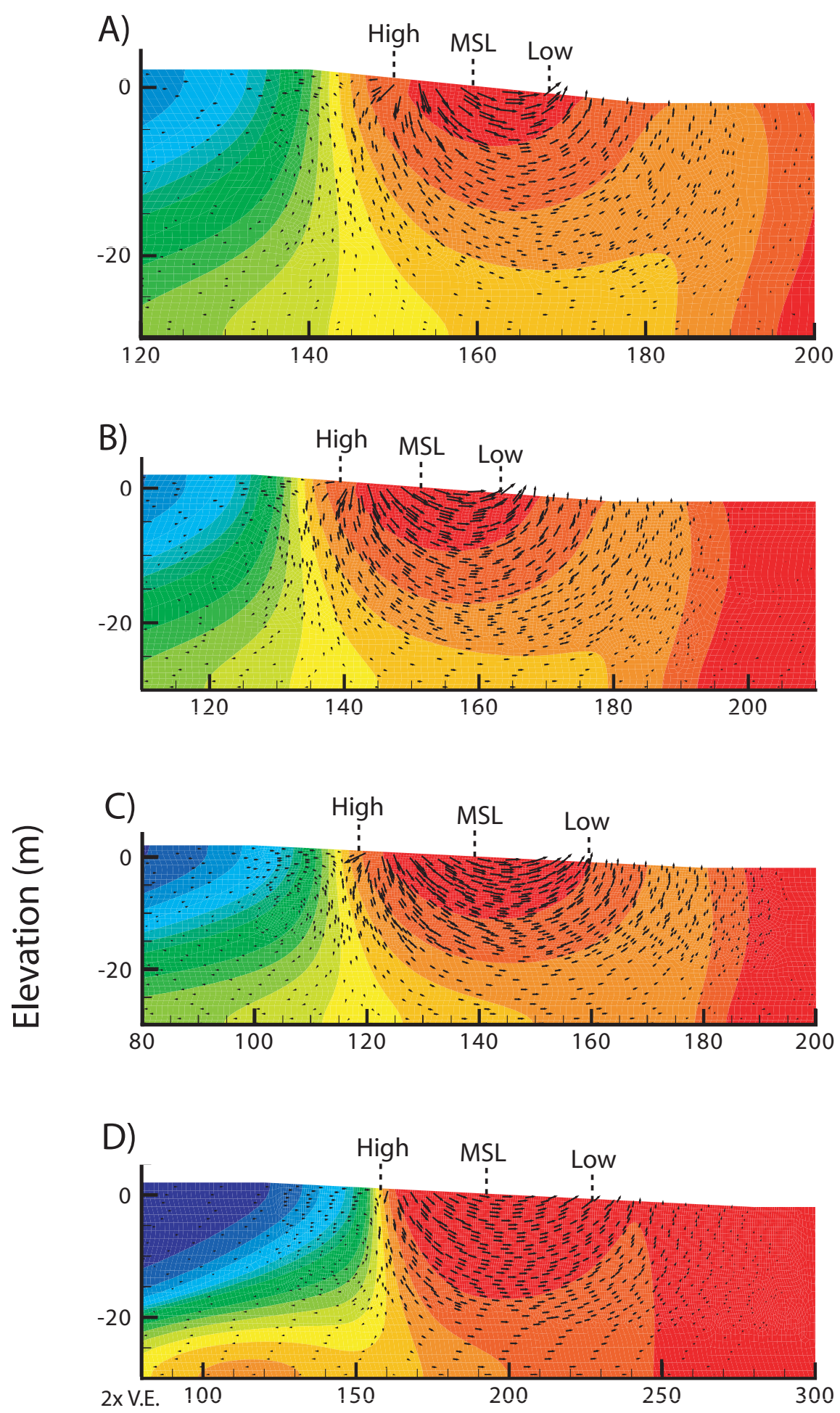

\begin{tabular}{|c|c|}
\hline \\
\hline \multicolumn{2}{|c|}{ Normalized Salinity } \\
\hline & 0.75 \\
\hline & 0.5 \\
\hline & 0.25 \\
\hline & 0 \\
\hline Average $\mathrm{V}$ & elocity \\
\hline & \\
\hline
\end{tabular}

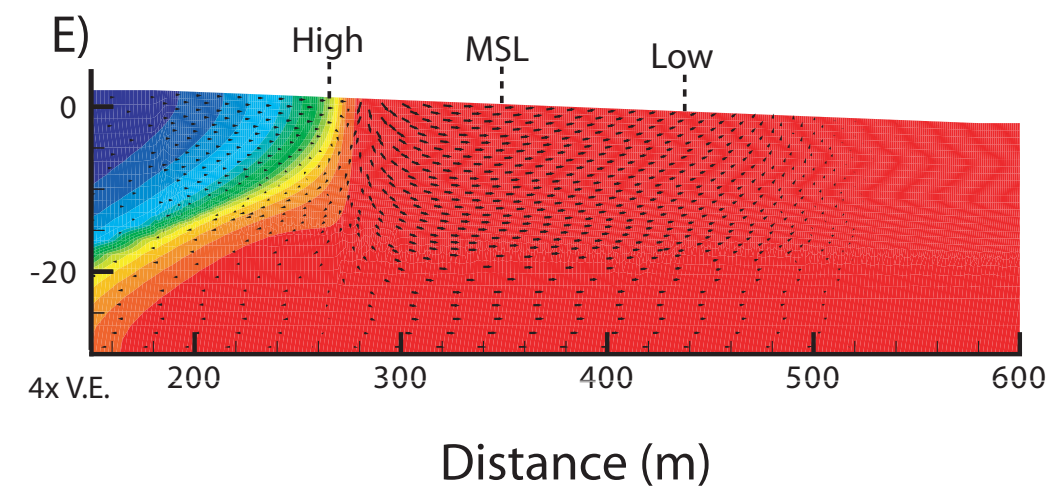

Figure 4 
a)

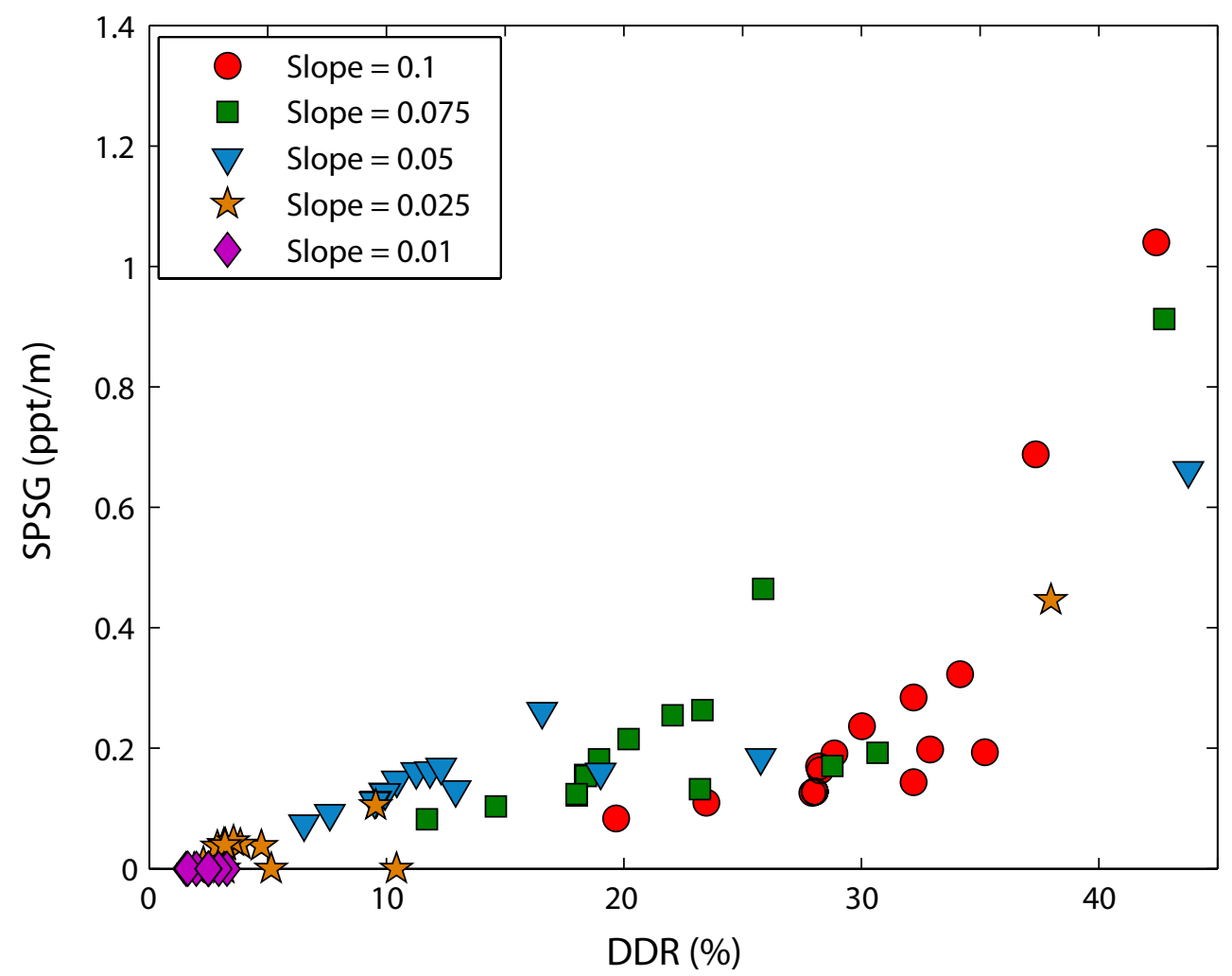

b)

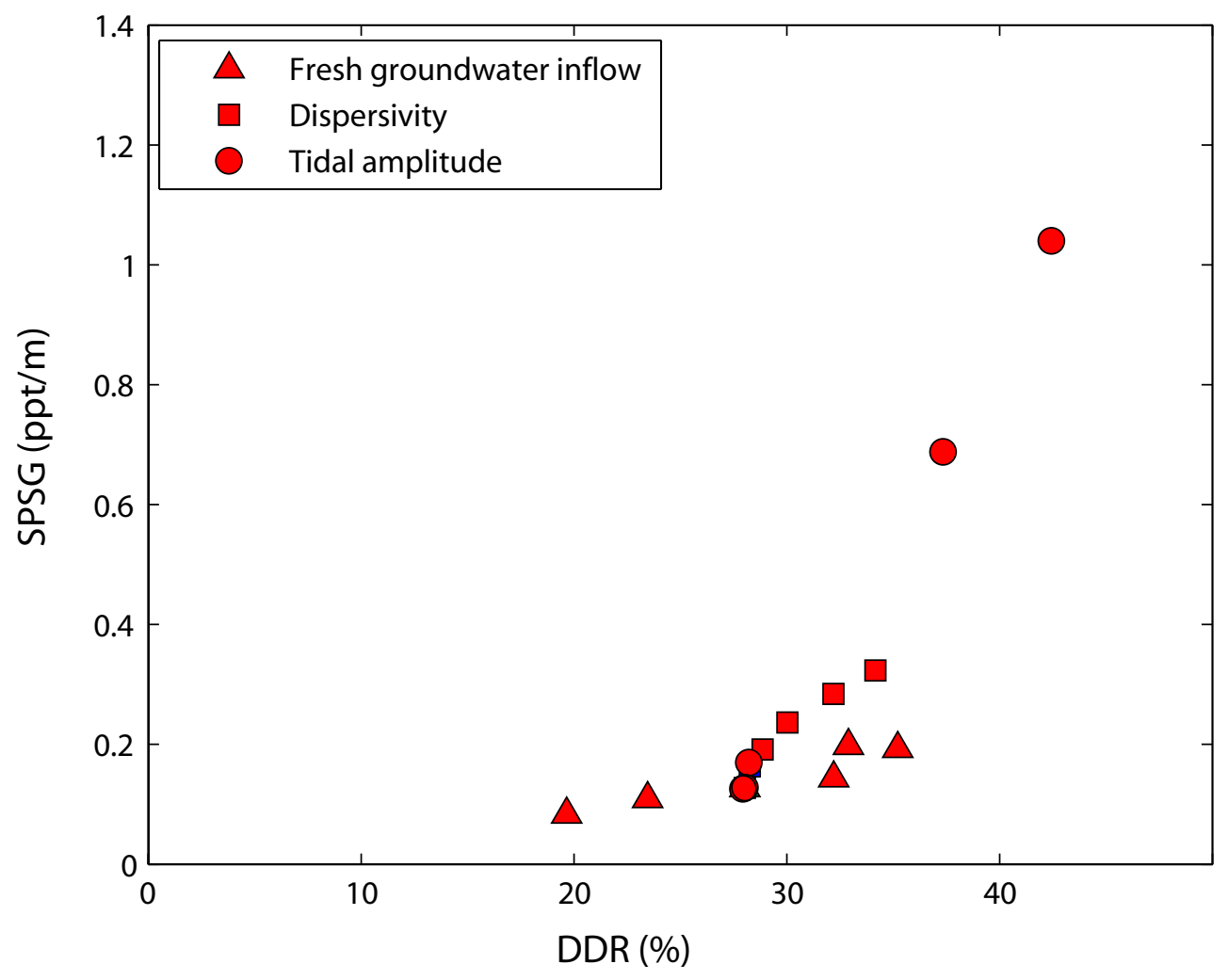

Figure 5 


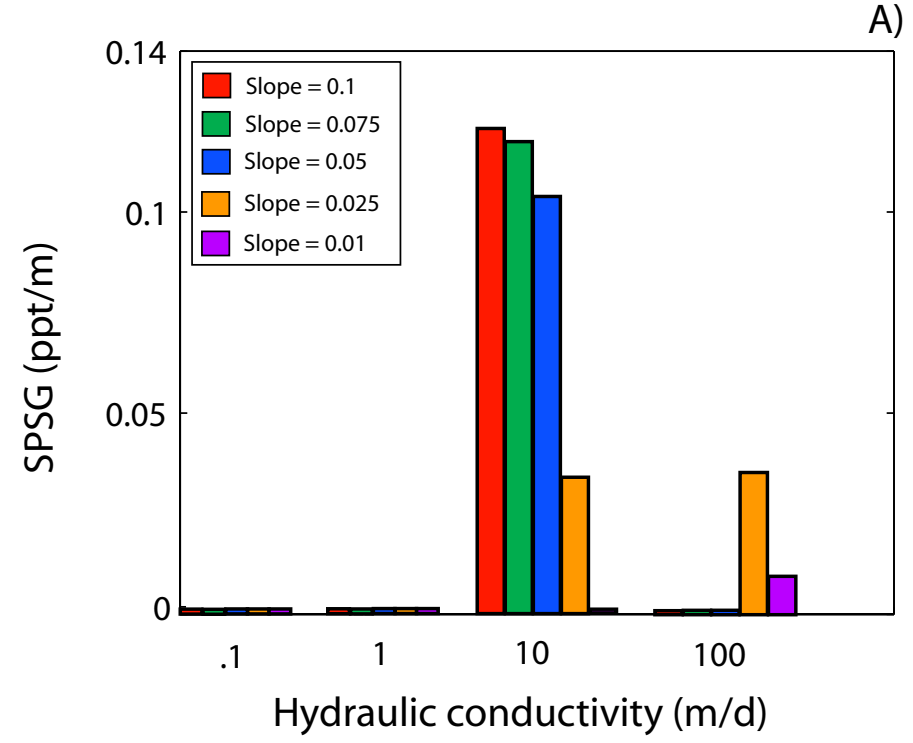

C)

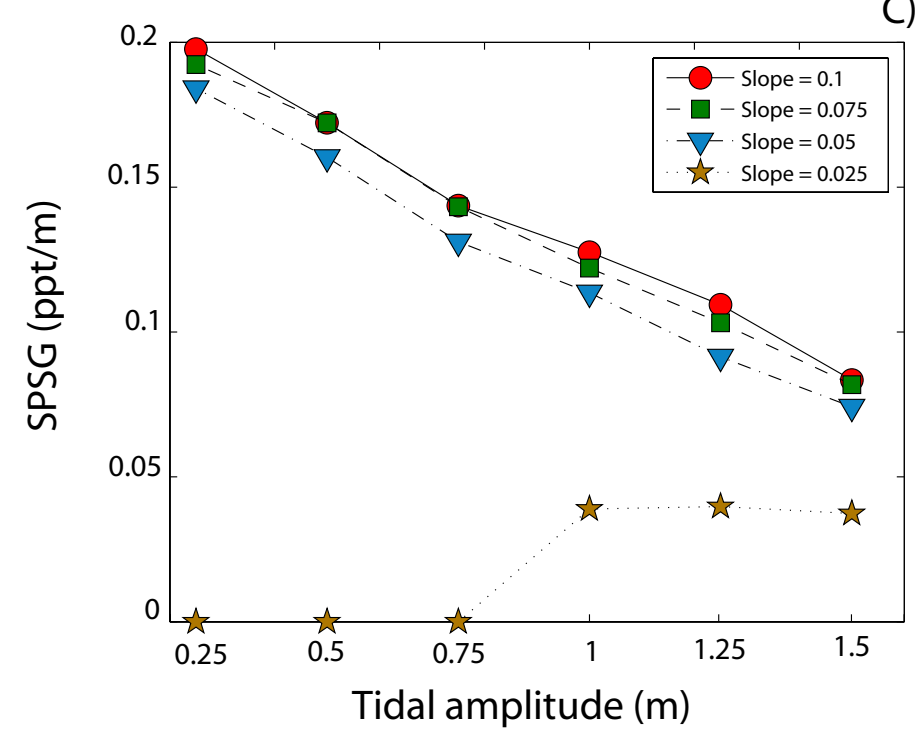

B)

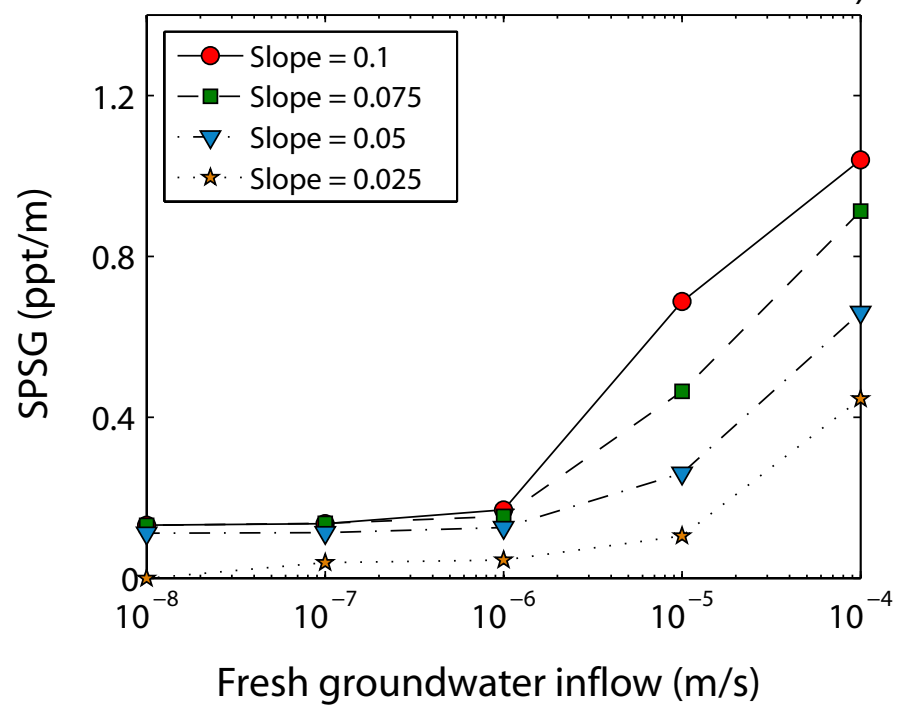

D)

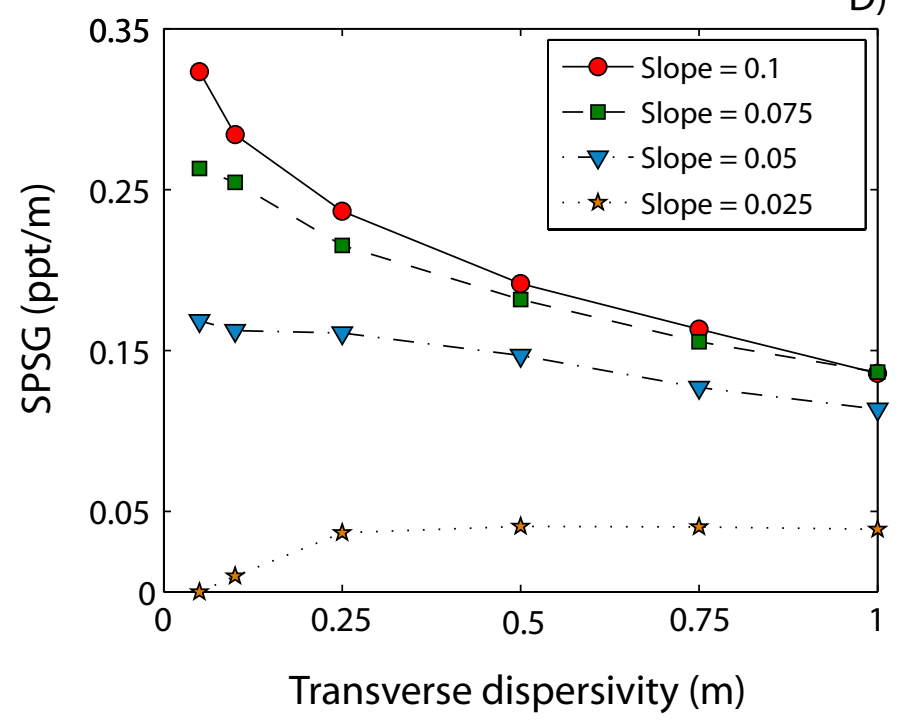




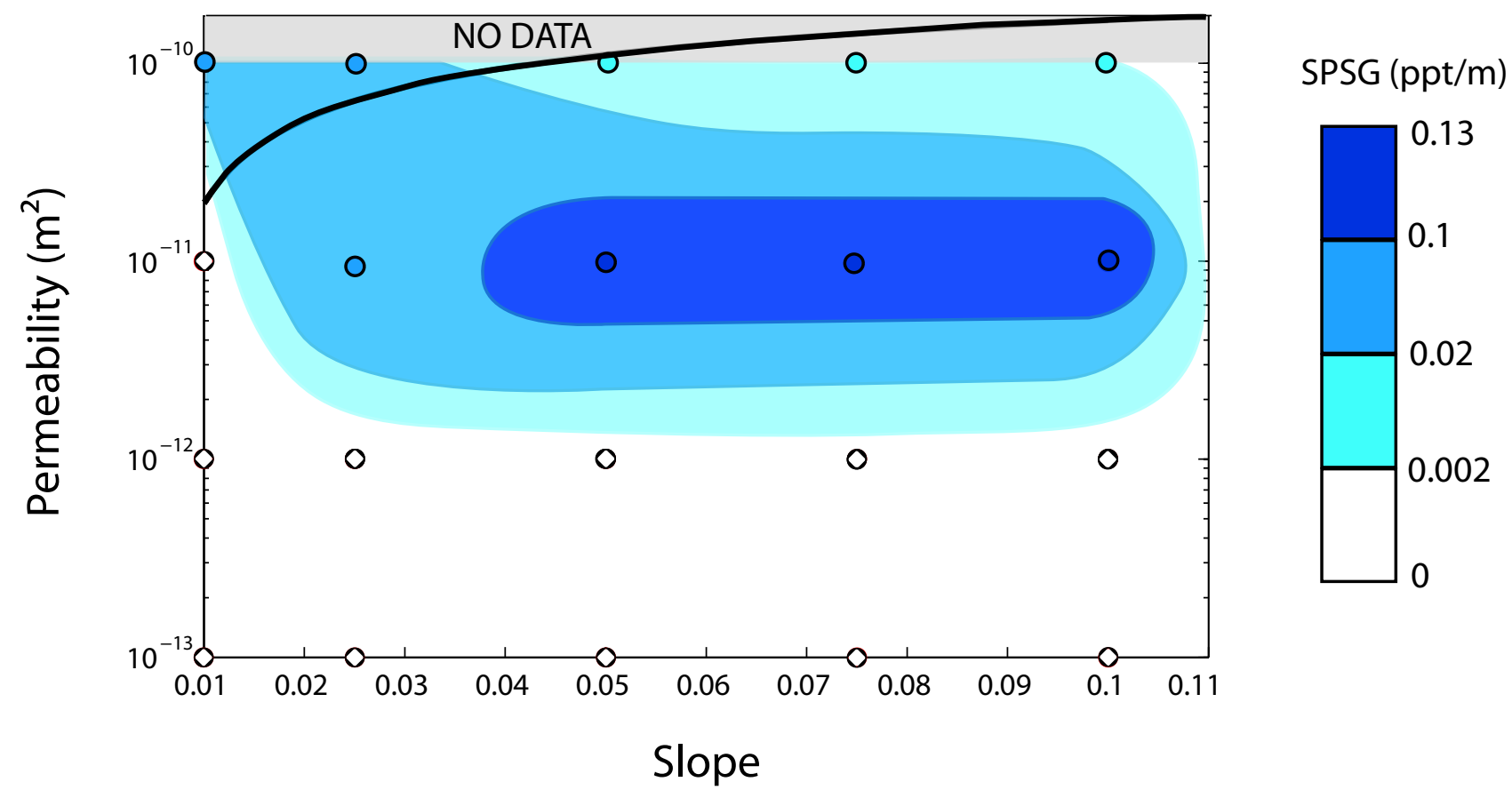

Figure 7 

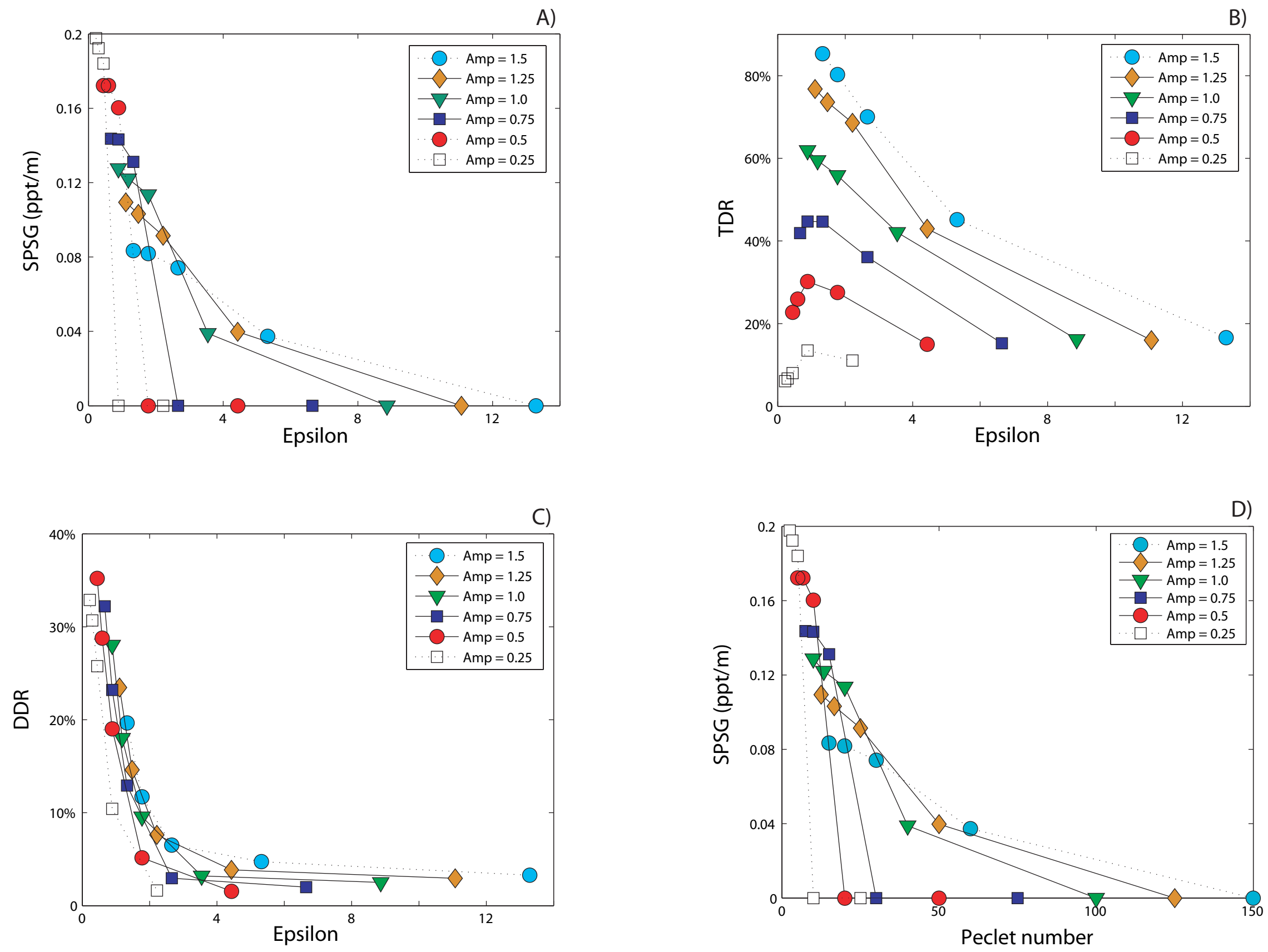

Figure 8 